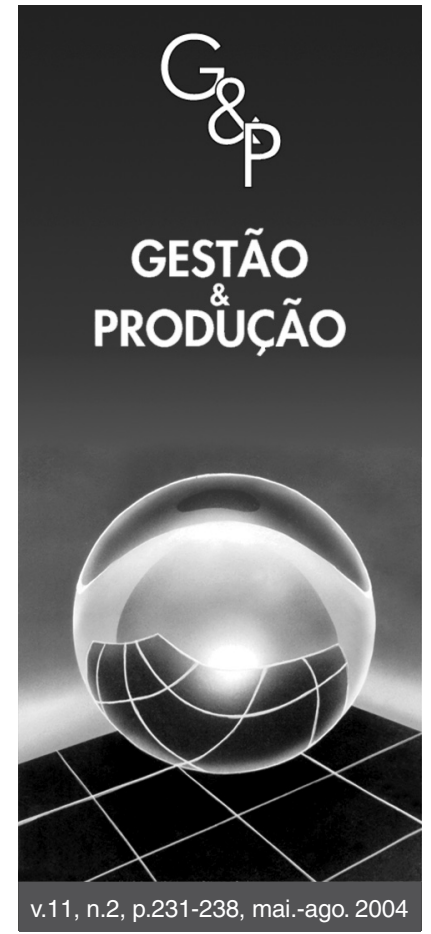

\section{FORESIGHT, INTELIGÊNCIA COMPETITIVA E GESTÃO DO CONHECIMENTO: INSTRUMENTOS PARA A GESTÃO DA INOVAÇÃO}

\section{Claudia Canongia}

Instituto Brasileiro de Informação em Ciência e Tecnologia (IBICT), Ministério da Ciência e Tecnologia (MCT), SAS Qd. 5 - Lt 6 - BI. H, 70.000-000, Brasília, DF, Brasil e-mail: canongia@eq.ufrj.br

Dalci M. Santos, Marcio M. Santos

Centro de Gestão e Estudos Estratégicos (CGEE), SCN Qd. 02 Bloco A, salas $1102 / 1103,11^{\circ}$ andar, Edifício Corporate Financial Center, 70712-900, Brasília, e-mails: DF dmsantos@cgee.org.br; mmiranda@cgee.org.br

Mauro Zackiewicz

Grupo de Estudos sobre Organização da Pesquisa e da Inovação (GEOPI), Departamento de Política Científica e Tecnológica, Instituto de Geociências (IG), Universidade Estadual de Campinas (Unicamp), C.P. 6152, CEP 13083-790,Campinas, SP, e-mail: maurozac@ige.unicamp.br

Recebido em: 03/7/2003 Aceito em: 18/3/2004

\title{
Resumo
}

A reflexão apresentada neste artigo busca contribuir para o aperfeiçoamento conceitual da gestão da inovação, destacando a necessidade de incrementar os processos de tomada de decisão e os efeitos de networking, como chaves para a promoção da capacidade de inovar e da competitividade das empresas. O artigo discute a aproximação de três abordagens particularmente úteis à gestão da inovação - Foresight, Inteligência Competitiva e Gestão do Conhecimento - e busca iniciar o entendimento de como as sinergias entre eles podem estimular uma cadeia de agregação de valor em conhecimento e influenciar, positivamente, os processos de tomada de decisão e de networking mencionados.

Palavras-chave: foresight, inteligência competitiva, gestão do conhecimento, gestão da inovação, gestão da competitividade.

\section{Introdução}

É crescente a percepção das empresas sobre a importância da gestão da inovação para a competitividade, porém as decisões relativas às estratégias de inovação ainda se ressentem do uso de instrumentos mais adequados para lidar com questões que surgem da própria essência dos processos de inovação: incerteza, timing, capacidade de análise de rotas alternativas, mobilização de competências, valorização da criatividade, entre outras. Neste texto, discutem-se possíveis aproximações e sinergias entre três abordagens úteis à gestão da inovação: os exercícios de technology foresight, a inteligência competitiva e a gestão do conhecimento. Buscase sintetizar as características das diferentes abordagens e discutir como elas, em uso conjunto, podem colaborar para o aperfeiçoamento de tomadas de decisão que pressupõem alta densidade de informação, além de promover um ambiente de estímulo à inovação.

Ainda que faltem estudos mais sistemáticos que considerem as possíveis convergências entre esses campos, em geral estabelecidos e desenvolvidos com pouco contato en- tre si, é possível perceber características comuns no que se refere a agregar valor à informação, estimular aprendizado contínuo e participação, e fortalecer os processos de interação entre pessoas e organizações, ainda que com ênfases distintas. Essa é a constatação que este artigo pretende explorar. Nesse sentido, pretende-se estimular a discussão entre especialistas dos três campos e o uso de metodologias, que conjuguem suas abordagens, para que sejam potencializados, na prática da gestão da inovação, os pontos fortes de cada uma.

\section{Decisões e networking no marco de gestão da inovação}

A capacidade de inovar é atualmente considerada uma das mais importantes características de organizações competitivas. Para isso, a busca sistemática por inovações radicais, ou seja, aquelas capazes de criar novos mercados e proporcionar rápida expansão produtiva e crescimento econômico, e por inovações incrementais, identificadas com processos de melhoria contínua, com "fazer melhor o que já se fazia", 
é fundamental para a sobrevivência das empresas.

O significado atual de competitividade engloba não somente a excelência de desempenho ou eficiência técnica das empresas ou produtos; compreende, também, a capacidade de desenvolver processos sistemáticos de busca por novas oportunidades, e superação de obstáculos técnicos e organizacionais via produção e aplicação de conhecimento. A gestão da inovação busca reunir os mecanismos e instrumentos, assim como as metodologias e formas de organização, que possam garantir a capacidade de inovar das organizações.

Competitividade não é um atributo exclusivamente interno às organizações, depende também do ambiente externo a elas. Da mesma forma, o desenvolvimento da capacidade de inovar não depende apenas de elementos internos das empresas, há sempre componentes dados pelo ambiente externo e decisões, que precisam ser tomados relativamente a ele. A capacidade de inovar depende também de condições objetivas dadas pela capacidade social de criar conhecimento do ambiente em que se insere a organização, incluindo a existência de competências específicas, de financiamento e de baixos custos de transação. Em outras palavras, da existência de sistemas de inovação bem constituídos (Lundvall, 2001).

Há, portanto, pelo menos dois níveis para se executar gestão da inovação. Um interno às organizações, ligado aos processos de identificação e construção de competências essenciais (core competences, Prahalad e Hamel, 1998), codificação e circulação do conhecimento, identificação de oportunidades e execução de uma estratégia adequada de integração desses processos com a $\mathrm{P} \& \mathrm{D}$ e a produção. E um nível externo à organização, ligado à capacidade de contratar e vender competências, captar recursos financeiros e interagir com organizações que possam contribuir para a produção interna de conhecimento na empresa, tais como universidades, institutos de pesquisa, fornecedores e mesmo empresas concorrentes.

Nesse contexto, o aparecimento da "organização em rede" é emblemático. A "sociedade do conhecimento, sociedade da informação ou economia do conhecimento" (Castells, 1996) é caracterizada pela explosão nos fluxos de informação e pelo compartilhamento de competências em redes estruturadas com atores heterogêneos intra e inter organizações. A noção de rede faz contraponto à visão tradicional do ambiente concorrencial, como um arquipélago de empresas em total isolamento, e do ambiente organizacional, como uma hierarquia taylorista de comandantes e comandados. A rede seria uma representação mais realista do ambiente que vem tomando forma desde a revolução das tecnologias de informação, iniciada na década de 1970, a expansão das empresas transnacionais e o fortalecimento das empresas intensivas em conhecimento. A "organização em rede" é ainda um tipo ideal, uma representação. Porém, a importância dessa abstração é indicar que uma nova lógica de organização, com atributos como horizontalidade, responsabilidades compartilhadas, procedimentos interativos de decisão e com parcerias com diversos atores externos, é uma tendência ine- rente que reflete mudanças de fundo nos meios de produção e nas bases da competitividade. Essa tendência transformada em processo consciente e intencional nas organizações configura o atributo de networking.

Os processos de decisão nessa nova lógica - a lógica da rede - tendem a ser cada vez mais transparentes, bem informados e participativos. Trata-se de legitimar ações e processos de coordenação, não apenas entre diversos níveis de hierarquia, mas, especialmente, entre as relações estabelecidas por contratos entre atores fora da hierarquia. Os desafios colocados à gestão da inovação estão essencialmente ligados à necessidade de se reconstruir conceitos e práticas na tomada de decisão, e na governança para criar e coordenar as redes internas e externas às organizações.

Para isso, duas tendências surgem com destaque: a ênfase num processo permanente de produção de conhecimento e de interação e negociação entre múltiplas instâncias, e a noção de que as decisões são eventos discretos, que emergem desse processo em momentos específicos, dando sentido ao próprio processo. A legitimidade das decisões nesses termos depende do compromisso manifesto daqueles que participam do processo. Assim, a construção da capacidade de inovação - que requer a mobilização das múltiplas instâncias - se viabiliza por um mecanismo de produção de decisões, informado por participação e acumulação de conhecimento.

As três abordagens, objetos de discussão neste artigo, têm muito a colaborar com a qualidade das decisões, com o desenvolvimento da "lógica de rede" e com a promoção de um ambiente favorável à inovação. O technology foresight é uma nova forma de executar e interpretar estudos do futuro, que utiliza muitas ferramentas usuais da prospecção tecnológica, mas as coloca a favor da criação de coordenação e compromisso de diferentes atores chaves, para viabilizar inovações. A inteligência competitiva pressupõe o desenvolvimento da capacidade de identificar, sistematizar e interpretar sinais do ambiente externo das organizações, para alimentar processos de decisão. A gestão do conhecimento enfatiza os mecanismos de compartilhamento, circulação e aperfeiçoamento dos conhecimentos produzidos numa organização. As três abordagens possuem importantes pontos de contato e, embora enfatizem certos aspectos diferentemente, são particularmente úteis à gestão da inovação.

A seguir, cada uma das três abordagens será apresentada em suas principais características e, em seguida, será proposto um modelo para conjugá-las, eficientemente, do ponto de vista da gestão da inovação.

\section{Foresight}

Até a década de 1980, as técnicas e métodos de technology forecasting procuravam determinar, com a melhor precisão possível, o futuro do desenvolvimento tecnológico e o aparecimento de novas tecnologias. De lá para cá, essa perspectiva foi, gradativamente, sendo alterada com crescente concordância de que o mais importante seria dotar as decisões presentes 
de conhecimento sobre as possibilidades de futuro, ao invés de determinar o futuro precisamente, para só então decidir. Essa sutil, porém importante diferença, modificou, profundamente, o conceito sobre o que é prospecção tecnológica e o modo de se trabalhar suas ferramentas na gestão da inovação. O nome Technology Foresight ou simplesmente Foresight passou a ser utilizado para denominar a nova abordagem.

Inicialmente, a abordagem ganhou espaço como instrumento de política de inovação, em diversos países (Johnston, 2002), por conta de sua característica de envolvimento de diferentes atores do sistema de inovação e promoção de networkig, para construção de compromisso e coordenação, acerca de prioridades nacionais de pesquisa e inovação.

Do ponto de vista da União Européia (Santos e Santos, 2003), Foresight é definido como uma atividade que conjuga três diferentes dimensões de um mesmo processo:

- Pensar o futuro: os possíveis eventos futuros são examinados a partir de tendências de longo prazo e especulações sobre fatos novos e inesperados. Para tanto, utilizam-se técnicas de forecasting, technology assessment, cenários, roadmaps, environmental scanning e outras. São monitoradas especialmente as tendências da ciência e da tecnologia, porém mudanças na economia, na sociedade, na geopolítica e na cultura são também variáveis consideradas;

- Debater o futuro: em geral, o processo de pensar o futuro no foresight é de natureza participativa e requer o envolvimento de diferentes stakeholders, incluindo autoridades públicas, empresas e organizações de pesquisa. Tal processo pode ocorrer em diferentes níveis: transnacional, nacional ou regional. Recentemente, grandes empresas têm também executado Foresights com envolvimento de seus funcionários e de atores externos a ela (Reger, 2001); e

- Modelar o futuro: A identificação de futuros possíveis e desejáveis e a interação e o aprendizado provocado nos participantes levam, paulatinamente, a decisões em diferentes níveis. Dessas decisões se espera sentido e coordenação dos esforços de materialização das visões de futuro construídas. Geralmente, obtêm-se resultados concretos dos estudos e discussões realizadas, e estes são sistematizados e dirigidos para a tomada de decisão em termos de macro diretrizes. Entretanto, o sucesso das ações concretas desenvolvidas depende fortemente das micro decisões dos atores envolvidos, e o processo é realizado de modo que o alinhamento do conjunto de decisões ocorra natural e progressivamente.

Análises e estudos recentes sobre as abordagens de Foresight (Barré, 2002) permitem observar que essa característica de produção simultânea de conhecimento e ação é um atributo em evolução, generalizando seu objeto - na origem mais ligada a aspectos tecnológicos - para a produção de conhecimento e inovação em amplo espectro. A expressão knowledge society foresight foi cunhada recentemente, para refletir essa ampliação no escopo de aplicação das abordagens de Foresight (Miles et al., 2002).
Apesar da orientação predominante das abordagens de Foresight ser a do fortalecimento de processos de governança, entre atores numa perspectiva de política pública em diversos níveis - regiões, países e blocos de países -, organizações privadas têm também buscado nesse referencial uma alternativa para reformar seus processos de decisão voltados à inovação. Reger (2001) mostra que essa assimilação se dá, justamente, pela consciência dessas empresas da necessidade de atuar em rede e interagir com outros atores dos sistemas de inovação, para manter e ampliar sua capacidade de inovar e competir.

Finalmente, quanto às suas abordagens metodológicas, os exercícios de Foresight, conforme exposto de forma esquemática por Horton (1999), consistem em três etapas que objetivam construir uma cadeia crescente de valor, em termos de conhecimento:

- Etapa 1: Mobilização de Insumos (ou Pré-Foresight). Corresponde às tarefas de coleta, organização e resumo das informações disponíveis sobre determinada tecnologia ou demanda, de identificação e mobilização de competências (especialistas) e de mapeamento dos demais atores relevantes ao sistema de inovação alvo. O resultado esperado é transformar as informações em conhecimento;

- Etapa 2: Visões de Futuro (ou Foresight). Trata-se em geral da aplicação de metodologias que promovam interação entre os atores, na discussão dos temas levantados no item anterior, de modo a obter conclusões ou opiniões sobre caminhos futuros. Destaca-se o uso da técnica Delphi ou de painéis para a consulta a especialistas, mas muitas variações metodológicas são possíveis. Nessa etapa, ocorrem processos de tradução e interpretação, acerca das tendências correntes e das possibilidades futuras. $\mathrm{O}$ resultado esperado é enriquecer o conhecimento existente, com um melhor entendimento dos condicionantes em jogo e das reais oportunidades de futuro; $\mathrm{e}$

-Etapa 3: Decisões e Ação (ou Pós-Foresight). Nessa etapa, procura-se reforçar o comprometimento dos atores que participaram da etapa anterior com as decisões que decorrerem dela, a partir de procedimentos de validação e de divulgação e assimilação para audiências mais amplas. $\mathrm{O}$ resultado esperado é transformar o entendimento acumulado em ações, e aproveitar o envolvimento dos atores para garantir a efetividade dessas ações.

\section{Inteligência Competitiva - IC}

Fuld (1994) apresenta o conceito de inteligência como informação analisada, que auxilia a tomada de decisão estratégica e tática. A palavra "competitiva" relaciona-se à aquisição de informações públicas e acessíveis sobre os concorrentes. Garcia Torres (1997) interpreta inteligência competitiva como um sistema de monitoramento (environmental scanning), definindo-a como um conjunto de procedimentos para coleta e análise de informação sobre o macro ambiente, que 
possibilitariam à organização um processo de aprendizagem contínuo, voltado ao planejamento e a decisões estratégicas.

Algumas das técnicas utilizadas no campo da Inteligência Competitiva são aplicáveis também para monitorar tendências tecnológicas e de inovação. Encontram, assim, valiosa aplicação especialmente na Etapa 1 dos exercícios de Foresight comentada acima, geralmente a mais trabalhosa e desafiadora, por conta do enorme volume disponível de informações e da comum desarticulação dessas mesmas informações.

A Inteligência Competitiva é um instrumento geralmente utilizado por empresas para eticamente identificar, coletar, sistematizar e interpretar informações relevantes sobre seu ambiente concorrencial. A capacidade computacional, dada pelos avanços nas tecnologias de informação, permite a fácil utilização de programas de computador para acesso e tratamento a bases de dados enormes, superando em muito a capacidade de cobertura possível por modos tradicionais de inspeção (Porter et al., 2002). A utilização do computador também abre portas para a implementação de algoritmos cada vez mais sofisticados, fazendo uso de recentes avanços no campo da inteligência artificial e mineração de dados, para o tratamento e identificação de padrões em bases de dados. Como exemplo, pode-se citar a redução de dados por meio de agrupamentos nebulosos (fuzzy c-means clustering), a análise de componentes principais (PCA), modelos de probabilidade bayesianos, redes neurais, dentre outros.

Martino (2003), comentando os recentes avanços metodológicos em prospecção tecnológica, destaca os enormes avanços e ganhos obtidos pelo uso do computador, para busca nos registros de patentes e de literatura científica disponíveis em bancos de dados cada vez mais especializados. Entretanto, é enfático ao afirmar que essas ferramentas e a automatização não eliminam a necessidade da análise especialista.

Assim como no Foresight, pode-se também compreender a Inteligência Competitiva como um processo organizacional, que envolve múltiplos participantes e stakeholders, múltiplos níveis e funções de uma organização, e que atua sobre as diversas perspectivas dos tomadores de decisão.

Entretanto, Ganeesh, Miree e Prescott (2003), em um extensivo mapeamento sobre a aplicação de processos de Inteligência Competitiva, afirmam que, talvez por conta da grande complexidade, ainda existem muitas dificuldades relativas ao entendimento e uso de Inteligência Competitiva, e sua implementação ocorre, em geral, com baixo nível de sofisticação em grandes empresas e de maneira ad hoc em pequenas empresas.

\section{Gestão do Conhecimento - GC}

A emergência dos instrumentos de Gestão do Conhecimento se dá a partir do deslocamento do eixo de produção de setores industriais tradicionais (intensivos em mão-deobra, matéria prima e maquinaria) para setores cujos produtos e/ou processos são cada vez mais intensivos em tecnologias de informação e conhecimento, nos quais os fluxos de informação, know how tecnológico e gerencial são fatores críticos de sucesso. A Gestão do Conhecimento pode ser sintetizada como um processo, articulado e intencional, destinado a sustentar ou a promover o desempenho global de uma organização, tendo como base a criação e a circulação de conhecimento (Salim, 2001).

Sveiby (2002) apresenta a seguinte classificação para abordar o campo da Gestão do Conhecimento, tanto em termos das áreas do conhecimento, que a compõem, como em relação aos níveis de percepção, que caracterizam o processo:

\section{Áreas do conhecimento:}

- Gestão da informação: envolve as áreas de tecnologia e ciência da informação, para a construção da base de conhecimento codificado; e

- Gestão de pessoas: envolve as áreas de filosofia, psicologia, sociologia e administração, para o entendimento da dinâmica dos processos de criação e difusão de conhecimento tácito.

\section{Níveis de percepção:}

- Perspectiva individual: inclui as motivações e as capacidades dos indivíduos; $\mathrm{e}$

- Perspectiva organizacional: inclui os recursos e as competências essenciais das organizações.

O entendimento sobre Gestão do Conhecimento também se sustenta nas proposições de autores como Sveiby (1998), Stewart (1998) e Edvinsson (1998), que sugerem diferentes nomenclaturas para as diferentes formas, pelas quais o conhecimento se manifesta e circula (Quadro 1). Esses três autores enfatizam que o valor das empresas vem se deslocando de seus ativos tangíveis para os intangíveis.

Os ativos intangíveis são determinantes da capacidade de inovação das empresas e da sua capacidade de aprendi-

\section{Quadro 1. Nomenclaturas para diferentes formas do conhecimento segundo diferentes autores.}

\begin{tabular}{llll}
\hline Formas do conhecimento & Sveiby & Stewart & Edvinsson \\
\hline $\begin{array}{l}\text { Patentes, marcas, tecnologias, modelos, } \\
\text { processos e conceitos organizacionais. }\end{array}$ & Estrutura interna & Capital estrutural & Capital organizacional \\
$\begin{array}{l}\text { Capacidade individual - habilidades, expe- } \\
\text { riências, talentos, conhecimentos tácitos. }\end{array}$ & Competências & Capital humano & Capital humano \\
$\begin{array}{l}\text { Relações com clientes, parceiros, fornece- } \\
\text { dores, imagem da organização. }\end{array}$ & Estrutura externa & Capital de clientes & Capital de clientes \\
\hline
\end{tabular}


zagem organizacional, como já notou Teece (1986). Mais que isso, torna-se, cada vez mais, fonte de valorização e credibilidade para as empresas. Desde a década de 1960, economistas como Schultz (1961) propuseram a figura do capital humano para destacar esse aspecto e, especialmente, procurar mensurá-lo monetariamente. Embora até hoje não se tenha atingido uma fórmula satisfatória, para mensurar a contribuição dos ativos intangíveis na composição do capital total das empresas, sua importância é reconhecida e sua contribuição pode ser indiretamente inferida, sempre que ocorrem saltos de competitividade em decorrência a inovações tecnológicas e organizacionais.

Na visão de Tapscott apud Santos et al. (2001), o conhecimento se tornaria um ativo na forma de capital intelectual que, por sua vez, existiria sob três formas e loci: a) a forma de conhecimento tácito, localizado no indivíduo; b) a forma de conhecimento adicional, localizado nas redes; e c) a forma de conhecimento codificado, localizado em livros, revistas, jornais, fotografias, bases de dados, internet, etc. $\mathrm{Na}$ literatura, percebe-se ainda a intenção de agregar um outro capital, o capital ambiental, cujo conceito guarda grande similaridade à capacidade da empresa de executar Inteligência Competitiva. Cavalcanti (2000) propõe, para a Gestão do Conhecimento, um modelo que considera quatro capitais de conhecimento, três ligados à gestão interna (capital estrutural, capital de relacionamento e capital intelectual) e outro à gestão externa (capital ambiental), configurando, assim, um modelo de negócios para a sociedade do conhecimento, denominado de Inteligência Empresarial.

Esses ativos altamente específicos das empresas, identificados como capitais de conhecimento ou capitais intelectuais, são a base para a capacidade de inovação. No sentido de promover a gestão da inovação, os instrumentos de Gestão do Conhecimento recuperam os elementos tácitos do conhecimento, inerentemente subjetivos e presentes horizontalmente nas organizações, e os põe a serviço dos diversos níveis de tomada de decisão, desde as decisões pulverizadas do dia-a-dia até as grandes diretrizes corporativas, valorizando-os como mais um ativo do conjunto de capitais da empresa.

Autores como Nonaka e Takeuchi (1995) e Davenport e Prusak (1998) desenvolveram modelos para explicar, respectivamente, como o conhecimento é criado e apropriado pelas empresas. Para Nonaka e Tekeuchi (1995), importam os mecanismos de compartilhamento e transferência de conhecimento tácito presente nos indivíduos para o conjunto da organização, na forma de conhecimentos explícitos (codificados). Esta, por sua vez, se desenvolveria numa perspectiva evolutiva, a partir do aporte continuado de conhecimentos vindos dos mais diversos pontos da empresa. Entretanto, para Davenport e Prusak (1998), a circulação de conhecimentos não é um processo natural, sua dinâmica guarda similaridade com os padrões de circulação de outros ativos. Nesse "mercado" de conhecimentos, elementos como capacidade de codificação, relações contratuais e direitos de propriedade intelectual precisam ser cuidadosamente gerenciados, para que ocorra equilíbrio virtuoso entre as forças em oposição da produção e da apropriação de conhecimentos pela empresa.

A tendência atual para assimilação e uso do conhecimento tácito é a criação de comunidades (geralmente por meio de intranets), promovendo a troca de experiências e idéias sobre questões de interesse das empresas, seja no âmbito técnico, de mercado ou estratégico. Os métodos e técnicas, utilizados na Gestão do Conhecimento, estimulam e justificam a cooperação entre as pessoas, e pressupõem que as estruturas organizacionais devam evoluir em consonância com as características e necessidades do capital intelectual. A identidade das competências essenciais de uma organização passa pelo reconhecimento da pertinência e importância de cada indivíduo que a compõe, e a Gestão de Conhecimento pode cumprir um importante papel nesse sentido. Por outro lado, as dificuldades apontadas por Davenport e Prusak (1998) reforçam a importância da existência de mecanismos de coordenação entre diferentes competências e instâncias, no sentido de efetivar a apropriação dos conhecimentos pela empresa, condição necessária para justificar seus investimentos em inovação.

\section{Um modelo de convergência para a gestão da inovação}

Como se pode perceber, existem convergências importantes entre as três abordagens apresentadas anteriormente. São elas:

- suas funções são semelhantes no sentido de obter informações e produzir conhecimento;

- seus resultados visam orientar a tomada de decisão;

- elas são direcionadas para fomentar organizações em rede;

- todas dão suporte à criação de condições para a inovação nas empresas; e

- elas não se configuram em estruturas metodológicas estanques; pelo contrário, estas possuem alto grau de flexibilidade e diferentes formas de internalização.

O Quadro 2 sintetiza as três abordagens, de modo a comparar seus objetivos específicos, os resultados pretendidos e as diferentes contribuições em relação à gestão da inovação nas organizações. A ênfase dada aos diferentes aspectos, que constituem o problema da gestão da inovação, destaca a complementaridade existente entre eles.

Para a gestão da inovação, as três abordagens podem cumprir papéis oportunamente complementares. Para facilitar a justificativa de um modelo de integração entre eles, a gestão da inovação é examinada por meio de dois aspectos centrais, o componente de tomada de decisão e o componente de networking.

A tomada de decisão na gestão de inovação não é um evento isolado e tampouco exclusivo dos altos escalões. Ela acontece em diferentes níveis e acompanha de perto o desenvolvimento dos ambientes interno e externo. A capacidade de resposta e a capacidade de aproveitar oportuni- 
Quadro 2. Visão sintética das três abordagens para a gestão da inovação.

\begin{tabular}{|c|c|c|c|}
\hline Abordagem & Foresight & Inteligência competitiva & Gestão do conhecimento \\
\hline Objetivos & $\begin{array}{l}\text { Integrar o planejamento estratégico, } \\
\text { os estudos de futuro e as estruturas } \\
\text { organizacionais, gerar sinergia nos } \\
\text { processos de inovação }\end{array}$ & $\begin{array}{l}\text { Manter ou criar vantagens compe- } \\
\text { titivas a partir da obtenção e uso } \\
\text { de informações estratégicas }\end{array}$ & $\begin{array}{l}\text { Promover inovação a partir do } \\
\text { estímulo ao potencial presente na } \\
\text { organização e da circulação do } \\
\text { conhecimento }\end{array}$ \\
\hline Principais resultados & $\begin{array}{l}\text { Governança dos processos de inova- } \\
\text { ção e decisões coordenadas }\end{array}$ & Decisões estratégicas informadas & $\begin{array}{l}\text { Desenvolvimento da capacidade } \\
\text { de inovar da organização }\end{array}$ \\
\hline $\begin{array}{l}\text { Importância na ges- } \\
\text { tão da inovação }\end{array}$ & $\begin{array}{l}\text { Ações em rede para subsidiar o plane- } \\
\text { jamento levando em conta visões de } \\
\text { futuro e o papel de diferentes organi- } \\
\text { zações (ou empresas) nessas visões }\end{array}$ & $\begin{array}{l}\text { Ações em rede voltadas para a } \\
\text { identificação das competências } \\
\text { externas e para mudanças no am- } \\
\text { biente de atuação da empresa }\end{array}$ & $\begin{array}{l}\text { Ações em rede voltadas para a } \\
\text { melhoria do potencial interno } \\
\text { de produção e codificação de } \\
\text { conhecimento da empresa }\end{array}$ \\
\hline
\end{tabular}

dades e inovar não podem estar subordinadas a processos centralizados de decisão. É evidente que o alto escalão não deixa de tomar decisões, afinal, fazer gestão da inovação não significa simplesmente inverter a lógica top-down, mas essas decisões precisam estar em consonância com as decisões do dia-a-dia, que podem gerar inovações importantes, e vice versa. Assim, a tomada de decisão precisa ser trabalhada em sua base, ou seja, na melhoria do conhecimento e sua disponibilização em todos os níveis, para dotar o conjunto de decisões de uma direção comum, muitas vezes até num consenso tácito. O conhecimento, que precisa ser promovido, envolve desde a capacidade de resolver problemas localmente até a percepção das tendências tecnológicas e sociais relevantes à empresa.

Das abordagens discutidas, a Gestão do Conhecimento promove a codificação e a circulação do conhecimento internamente, enquanto a Inteligência Competitiva fornece meios para adquirir conhecimento sobre o ambiente externo, conhecimento esse que pode ser, em grande parte, introduzido na rede interna de circulação. Um exercício de Foresight, desenhado para gerar coordenação nas decisões sobre inovação, encontraria condições ótimas de realização em uma organização com Gestão de Conhecimento e Inteligência Competitiva desenvolvidas. Caso contrário, um exercício desse tipo pode estimular a implantação das demais abordagens. A execução de um Foresight implica em examinar com profundidade as alternativas de ação - isso consome enorme trabalho intelectual - por meio de monitoramentos internos e externos às organizações, análise de informações, envolvimento de pessoas e síntese entre conhecimentos tácitos e codificados.

Por sua vez, a promoção de networking é um trunfo tanto para o estabelecimento efetivo de comunicação das empresas com universidades, instituições públicas de pesquisa e agências de financiamento de pesquisa e inovação, quanto para lograr ganhos de escala e escopo na aquisição de conhecimento e viabilização de inovações. A participação em redes também ajuda na ampliação da capacidade de percepção, acerca das tendências de tecnologias e mercados e de seus impactos na sociedade e no meio ambiente. Os exercícios de Foresight pressupõem esse tipo de interação e podem ser utilizados até como mecanismos para identificar competências essenciais, e sinalizá-las para a rede. As ferramentas de Inteligência Competitiva têm um importante papel para subsidiar a empresa no processo de interação com outros atores de um sistema de inovação, de modo que haja ganhos, em termos de aprendizado e identificação de oportunidades e preservação de informações e projetos estratégicos. Internamente, o networking corresponde à própria essência da circulação de conhecimento e é o principal mecanismo de ação da Gestão do Conhecimento.

A Figura 1 mostra a proposição de um modelo conceitual para integrar as três abordagens na gestão da inovação. A adoção conjunta delas permite alimentar sucessivamente a cadeia de valor de conhecimento, que vai do monitoramento do ambiente externo às decisões bem informadas e coordenadas no ambiente interno. As interfaces entre suas especificidades correspondem aproximadamente à interface entre os ambientes interno e externo, passando por uma instância mediadora de coordenação, que, na realidade, corresponde às características institucionais de sistema de inovação, em que se insere a empresa.

É nessa instância intermediária que atua o Foresight. Em analogia, Inteligência Competitiva e Gestão de Conhecimento poderiam ser respectivamente identificadas com as Fases 1 e 3 do processo de Foresight, quando aplicado a empresas. Claro que em empresas, os resultados do Foresight em termos de coordenação, criação de compromissos e comprometimento dos envolvidos, compreensão das forças atuantes na construção do futuro e concentração em prioridades consensuais rebatem diretamente nos processos de decisão internos. Entretanto, esse processo, necessariamente, é construído a partir da interação com o exterior e com outros atores, no mercado e na sociedade.

Finalmente, restaria comentar as possibilidades metodológicas, que a concatenação dessas abordagens trazem à gestão da inovação, e sua adequação a diferentes necessidades de aplicação. Atualmente, a prática consiste em adotar procedimentos e ferramentas sem muita atenção à perspectiva de integração, perdendo a oportunidade de obter sinergias que beneficiem sistemicamente a capacidade de inovar, nos mo- 


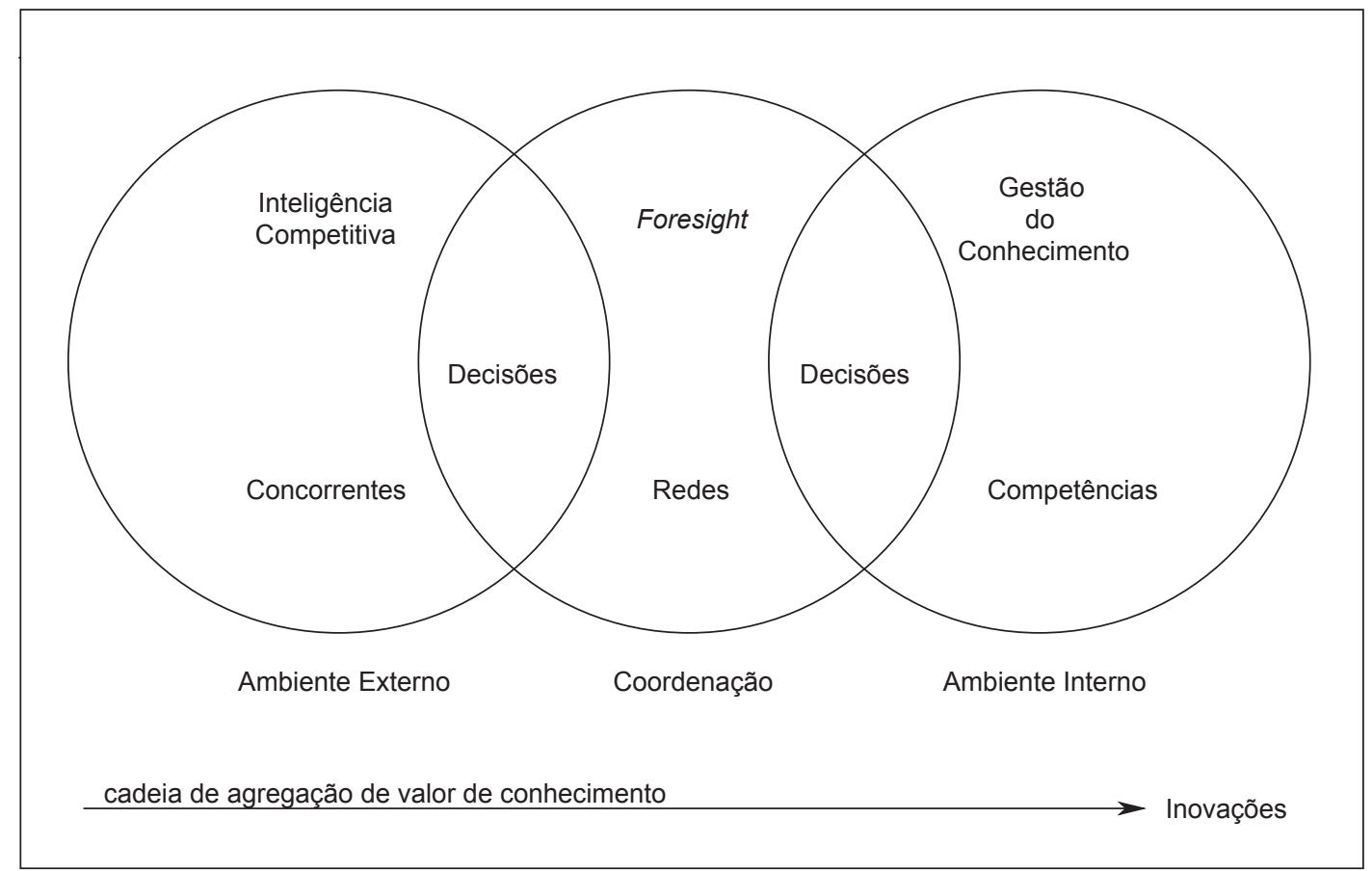

Figura 1. Modelo de integração das três abordagens na gestão da inovação.

dos que foram sugeridos neste artigo. Esse é um ponto que tem muito ainda a ser explorado. A integração entre essas abordagens e suas diferentes técnicas fazem parte da agenda atual de diversos grupos de pesquisa sobre organizações e gestão da inovação. Dentre as aproximações entre técnicas a serem exploradas se destacam: a integração de métodos de apoio à decisão, com técnicas avançadas de monitoramento e tratamento de bases de dados; uso de técnicas de constru- ção e acompanhamento perene de cenários de inovação e a incorporação de conhecimento tácito de especialistas em sistemas inteligentes de busca. Pelo flanco conceitual, estudos de caso podem esclarecer, com maior detalhamento, os efeitos provocados pelo uso dessas abordagens e de sua composição, sobre a organização dos processos de inovação nas empresas, e sugerir procedimentos e avanços metodológicos para se lograr os resultados pretendidos.

\section{Referências Bibliográficas}

BARRÉ, R. Foresights and their Themes: Analysis, Typology and Perspectives. In.: The Role of Foresight in the Selection of Research Policy Priorities. Espanha. Sevilha. 13-14 Maio 2002.

CASTELLS, M. The rise of the Network Society. USA, Blackwell Publications, 1996.

CAVALCANTI, M.; GOMES, E. A nova riqueza das organizações: os capitais do conhecimento. Revista TN Petróleo. n. 16, ano 3, 2000.

CANONGIA, C. Gestão do Conhecimento e a Competitividade - Reflexão. Centro de Gestão e Estudos Estratégicos (CGEE). Brasília: CGEE, 2002.

DAVENPORT, T. H.; PRUSAK, L. Working Knowledge How Organisations Manages What They Know. Boston: Havard Business School Press, 1998.

EDVINSSON, L. Capital Intelectual: descobrindo o valor real de sua empresa pela identificação de seus valores in- ternos. Rio de Janeiro: Makron Books, 1998.

FULD, L. M. The New Competitor Intelligence: the complete resource for finding, analyzing, and using information about your competitors. New York: John Wiley \& Sons, Inc. p. 23 - 27. 1994.

GANESH, U; MIREE; Cynthia, E; PRESCOTT, J. Competitive Intelligence Field Research: Moving the Field forward by setting a Research Agenda. Journal of Competitive Intelligence and Management, v. 1, n. 1, 2003.

GARCIA, T. D. Seminário de Inteligência Competitiva: informação e conhecimento. México: Innestec. p. 21, 1997.

HORTON, A. A Simple Guide to Sucessful Foresight. Foresight, v. 1, n. 1, p. 5-9, 1999.

JOHNSTON, R. The State and Contribution of International Foresight: New Challenges. The Role of Foresight in the Selection of Research Policy Priorities (Conference Papers), p. 59-74. Seville, 13-14 May, 2002. 
LUNDVALL, B. Políticas de Inovação na Economia do Aprendizado. Parcerias Estratégicas, n. 10, p.200-218, 2001.

MARTINO, J. P. A review of selected recent advances in technological forecasting. Technological Forecasting and Social Change, n. 70, p. 719-733, 2003.

MILES, I.; KEENAN, M.; KAIVO-OJA, J. Handbook of knowledge society foresight. Prest, Manchester, 2002.

NONAKA, I.; TAKEUCHI, H.. The knowledge Creating Company. Oxford University Press, New York, 1995.

PORTER, A.L.; KONGTHON, A.; LU, J.C. Research Profiling: Improving the literature review. Scientometrics, v. 53, n. 3, p. 351-370, 2002.

PRAHALAD, C. K.; HAMEL, G. A competência essencial da coorporação. In: MONTGOMERY, C.; PORTER, M. (Eds.). Estratégia - A busca da vantagem competitiva. Rio de Janeiro: Ed. Campus, 1998.

REGER, G. Technology Foresight in Companies: From an Indicator to a Network and Process Perspective. Technology \& Strategic Management, v. 13, n. 4, 2001.
SALIM, J.J. Palestra Gestão do Conhecimento e Transformação Organizacional, In: $\mathbf{6 8}^{\mathbf{a}}$ Semana da EQ/UFRJ, Rio de Janeiro. Agosto. 2001.

SANTOS, A.R.; PACHECO, F.F.; PEREIRA, H. J.; BASTOS Jr, P.A. Gestão do conhecimento como modelo empresarial. Gestão do conhecimento: uma experiência para o sucesso empresarial. Rio de Janeiro: Campus. 2001.

SANTOS, D.M.; SANTOS, M.M. A atividade de foresight e a União Européia (EU). Parcerias Estratégicas, n. 17, p. 165-192, 2003.

SCHULTZ, T. Investment in Human Capital. American Economic Review, v. 51, 1961.

STEWART, T. Capital Intelectual. Rio de janeiro: Campus. 1998

SVEIBY, K. A nova riqueza das organizações, Rio de Janeiro: Campus, 1998

TEECE, D. Profiting from technological innovation: implications for integration, collaboration, licensing an public policy. Research Policy, v. 15, n. 6, p. 285-305, 1986.

\section{FORESIGHT, COMPETITIVE INTELLIGENCE AND KNOWLEDGE MANAGEMENT AS INNOVATION MANAGEMENT TOOLS}

\section{Abstract:}

The reflections in this article aim to contribute toward the conceptual improvement of innovation management practices, highlighting the need to enhance decision making processes and the effects of networking as key factors for the promotion of a company's innovation capabilities and competitiveness. The article discusses the connection between three particularly useful approaches for innovation management - Foresight, Competitive Intelligence and Knowledge Management, arguing that their simultaneous use can generate a chain of added knowledge value, thereby positively influencing the aforementioned decision making processes and networking effects.

Keywords: Foresight, competitive intelligence, knowledge management, innovation management, competitiveness management. 